\title{
Señales y discernimiento en el evangelio de Juan
}

\author{
Juan Barreto, \\ Universidad de La Laguna, Tenerife, \\ Centro de Reflexión Teológica, San Salvador.
}

\section{Una experiencia inquietante}

El evangelio de Juan focaliza, más que ningún otro, la naturaleza conflictiva de la relación de Jesús y su comunidad con su medio(1). Refleja, sin duda, laceraciones dramáticas en el proceso de formación de la comunidad, la constatación de que las posturas contrastantes se dan no sólo entre aquellos que rechazaron y aceptaron a Jesús, sino también entre los que se mostraron dispuestos a creer en él (Jn 2, $23-3,12 ; 7,3-8 ; 8,30-38$ ). En consecuencia, la preocupación central en torno a la cual se estructura todo el evangelio es la respuesta a estas preguntas: ¿quién es Jesús?, ¿cuáles son los criterios para interpretar sus palabras y sus hechos $y$, entre éstos, sobre todo su muerte?

Que las mismas actitudes, los mismos hechos, la misma muerte, sean interpretados tan diversamente, sigue siendo una experiencia inquietante en la Iglesia de hoy. Baste recordar las opiniones tan dispares emitidas en torno a la figura y muerte de Mons. Romero o de los jesuitas de la UCA, acribillados a balazos, o de tantos otros que fueron asesinados en circunstancias similares. Las interpretaciones opuestas no vienen sólo de círculos no creyentes, sino que proceden también de los que profesan la misma fe en Jesús e, incluso, de sectores de la jerarquía que dicen hablar en su nombre. Para unos, son mártires que han seguido

1. Una de las caracteristicas más notables del cuarto evangelio es, en efecto, la conciencia del impacto conflictivo de Jesús con su medio y la vigorosa expresión del mismo a través de imágenes polares como: vida-muerte, luz-tiniebla, arriba (esfera divina, cielo)-abajo (esfera de lo caduco, terrestre), que colorean todo el evangelio y que sitúan el conflicto entre Jesús y el sistema religioso de su tiempo como culmen del conflicto radical y permanente que recorre toda la historia. 
las huellas de su maestro, signos de su modo de estar en medio de los hombres junto a los más débiles, hasta el extremo de dar, como él, la propia vida. Para otros, por el contrario, fueron víctimas de sus propios errores, al confundir -dicenla misión evangelizadora con la actividad política y social; según éstos, murieron por ideologias puramente humanas, haciéndose, además, culpables de dividir a la comunidad.

\section{Las acciones de Jesús y la pluralidad de interpretaciones}

El evangelio de Juan asume la forma literaria de un alegato testimonial sobre la actividad de Jesús. Ciertamente, Jesús realizó, todavía en presencia de sus discípulos, "otras muchas señales que no están escritas en este libro. Estas quedan escritas para que crean que Jesús es el Mesías, el Hijo de Dios, y, creyendo, tengan vida" $(20,30 s ; c f r .21,24 s)$.

Las obras son presentadas, por tanto, como "señales"; y, según Juan, contienen una indicación que, de ser percibida, habría de llevar al sentido de la persona y obra de Jesús, sobre todo al sentido de su muerte. Este sentido último se expresa en el evangelio con la simbología veterotestamentaria de la "gloria" o transparencia divina en él: "plenitud de amor y lealtad"(2) (1, 14; 17, 1-5). La "gloria" alcanza el momento cumbre de transparencia (la "hora" según la terminología joanea)(3) en el acontecimiento de la muerte $(12,23.27 \mathrm{~s} ; 13,31 ; 17,1$; cfr. 2,4$)$.

Pero asimismo, Juan constata que esa lectura de los hechos no se produce automáticamente; que no s6́lo no todos perciben la transparencia de la gloria del Padre en las obras de Jesús, sino que muchos las reputan obras de un embaucador y pecador. Para los dirigentes judíos, la actuación de Jesús constituye no sólo un peligro para el sistema religioso que representan y dirigen: " $Q Q u e ́$ hacemos? Este hombre realiza muchas señales. Si lo dejamos seguir así, todos van a darle su adhesión y vendrán los romanos y quitarán de en medio nuestro lugar sagrado e incluso nuestra nación" (11, 47s). A la multilud que le sigue hasta el acoso después de ser alimentada en el desierto, Jesús le reprocha: "Sí, se lo aseguro. Ustedes no me buscan por haber visto señales, sino por haber comido pan hasta

2. La expresión describe el contenido de la "gloria" y traduce la griega charis kai alêtheia (I, 14.17), que, a su vez, es la versión de la hebrea hesed weemet. Tanto en griego como en hebreo, la coordinación tiene valor hendiádico, esto es, los dos términos se refieren no a dos realidades, sino a la misma, y el segundo, con valor adjetival, expresa la calidad del primero (amor fiel); prueba de ello es que en 1,16 sólo se menciona el primero (charis). Para la justificación de esta traduccion, cfr. J. MateosJ. Barreto, El evangelio de Juan, análisis lingüístico y comentario exegérico, Madrid 3. ed. 1992, pp. 46s.

3. Cfr. "Gloria" y "Hora" en, J. Mateos-J.Barreto, Vocabulario Teológico del Evangelio de Juan, Madrid 1980, pp. 124-128 y 145, 147 respectivamente. 
saciarse" $(6,26)$. Los panes y los peces repartidos constituyen una señal, cuyo sentido la multitud no habfa percibido. En efecto, habfan visto en ella una manifestación de un poder que pretendieron poner a su servicio. Por eso, lo quisieron hacer rey por la fuerza. Y Jesús huyó: "Aquellos hombres, al ver la señal que había realizado, decian: 'Ciertamente éste es el profeta, el que tenía que venir al mundo'. Jesús entonces, dándose cuenta de que iban a llevárselo por la fuerza para hacerlo rey, se retiró de nuevo al monte, él solo" $(6,14 s)$.

La misma proclividad a interpretar a Dios desde la clave del poder y exigirle actuaciones en este sentido es denunciada por Jesús repetidamente $(4,48 s ; 7$, 3s). Es, pues, lógico que no aceplara cualquier adhesión a su persona, que sus gestos pudieran provocar: "Mientras estaba en Jerusalén, durante las fiestas de Pascua, muchos prestaron adhesión a su figura al presenciar las señales que realizaba. Pero Jesús no se fiaba de ellos, por conocerlos a todos" $(2,23 s)$.

\section{Criterios de discernimiento}

Juan no sólo presenta las obras de Jesús, sino que, al mismo tiempo, ofrece la significación de las mismas, es decir, su carácter de "señales"; describe, asi, las claves de interpretación, los criterios de discernimiento de la actividad de Jesús.

En las secciones Juan 5 y $9-10$ se ejemplifica la reacción de los dirigentes judíos y sus motivaciones frente a sendas acciones de Jesús. Los dos episodios son paralelos y habria que entenderlos superponiendo las lecturas. Los destinatarios de la actuación de Jesús son un paralítico y un ciego respectivamente. Ambas categorfas, cojos y ciegos, se presentan en la tradición bíblica habitualmente como el paradigma del hombre mutilado y necesitado de salvación(4). Tanto en uno como en otro pasaje, a la intervención de Jesús sigue una discusión sobre las causas de su actuación y sobre el porqué de la reacción de sus adversarios. Nos vamos a centrar en ellos.

4. En el Antiguo Testamento con frecuencia aparecen emparejadas estas dos calegorfas: bien como prototipos de hombres débiles y, por lo mismo, necesitados de asistencia (Jb 29, 15), o, al contrario, inútiles, dignos de desprecio (2 Sam 5, 6-8), ineplos para las funciones sacerdotales (Lv 21,18 ) e, incluso, indignos de entrar en el templo (2Sam 5, 8); o bien. como prototipos de hombres oprimidos y, por lo mismo, destinatarios de la acción liberadora del Señor, imagen del pueblo abatido (Is 35, $5 \mathrm{~s}$; cfr. 29, 18; 42, 7.18-20; 43, 8; 59, 10; Sal 146, 8). El mismo emparejamiento de ciegos y cojos en Mt 11, 5 . 


\subsection{Juan 5}

El texto describe, en primer lugar, los destinatarios de la actividad(5) de Jesús (6). La descripción es paradigmática: ciegos, tullidos, resecos, la gran multitud excluida, que no puede participar en la fiesta, es la imagen del pueblo. A ella, representada en el prototipo del paralítico, Jesús le ofrece la salvación. Pero lo hace en tiempo de "descanso"(7), por definición, tiempo consagrado a Dios y sólo a él.

Ante el escándalo de los judíos, Jesús explica su actuación: "Mi Padre, hasta el presente, sigue trabajando y yo también trabajo" $(5,17)$. Apela a la aclividad del Padre (no meramente de Dios), a la que considera no interrumpida hasta el presente (se ha de entender desde el principio de la creación). Establece así un principio: el criterio para saber qué debe hacerse y qué no, para distinguir lo bueno de lo malo, es el modo de actuar del Padre. Ahora bien, la actividad creadora del Padre es lógicamente anterior a la ley, la fundamenta y la explica.

Esto implica que, para Jesús, Dios es ante todo Padre y que, como creador y dador de vida, su relación con el hombre, fundante de todas las demás, es su actividad creadora continua. La actividad legisladora de Dios es subsidiaria de ésı. De hecho, lo que el Padre enseña al Hijo en primer término y cuyo aprendizaje lo caracteriza como tal Hijo, no es un código de preceptos, sino su modo de obrar: un hijo no puede hacer nada de por sí, tiene que vérselo hacer al Padre. Así, cualquier cosa que éste haga, también el hijo la hace igual, porque "el Padre quiere al hijo y le enseña todo lo que él hace. Y le enseñará obras mayores que éstas para asombro de ustedes" (5, 19s).

5. Nótese que en el evangelio de Juan Jesús es el realizador de signos de salvación, no un mero maestro portador de verdades a enseñar, y que el libro como tal se presenta como una recopilación de hechos-señales (Jn 20,30s; 21, 25). De hecho, la axiología de la realización (causa-cumplimiento) recorre, como su espina dorsal, todo el relato evangélico emparejada a la axiologla temporal (principio-fin). En tomo a ella se organizan la serie de roles temáticos, que constituyen la trama narrativa. Baste mencionar el papel de la Palabra como agente realizador (1, 3-5.9.12.17); en el resto del relato evangélico se entiende a Jesús como el realizador de la "obra" (ıo ergon: 4, 34; 17, 14) u "obras" (ta erga: 5, 20.36; 9, 3.4; 10, 25.32.37s; 14, 10ss; 15, 24) del Padre; se menciona su "trabajo" en sintonía con el Padre (ergazomai: 5,17); se insiste en el "cumplimiento" o realización que lleva a cabo (teleioô: 4,$34 ; 5,36 ; 17,4$; cfr. teleô: 19, 28.30).

6. Cfr. Juan Barreto, La iradición del discípulo amado. Madrid 1989. pp. 29-45.

7. En la expresión, propia de Juan, ên de sabbaton en ekeinê tê hêmerô, la palabra "sabbaton" translitera el hebreo sabbaton que significa descanso, sea en día sábado (Ex 16, 23) sea en otro día festivo (Lv 23, 24.39). Para el día sábado, que no aparece en Juan, los sin6́pticos usan la forma plural: tois sabbasin (Mt 12, 5). hê hêmera tôn sabbatôn (Lc 4, 16). Juan, pues, quiere llamar la atención sobre el hecho mismo del descanso obligatorio y contraponerlo al trabajo del Padre. 
Desde la perspectiva de Jesús se sigue que el tiempo consagrado a Dios (al Padre) no se puede interpretar como tiempo de inactividad en favor del hombre. Consagrar el tiempo a Dios significa asociarse a su actividad creadora continuada. Por el contrario, según los dirigentes judios, el punto de referencia cardinal para juzgar la actuación del hombre es la ley de Dios, expresión del derecho divino sobre el hombre. La relación fundamental de Dios con el hombre se concreta en el ejercicio de su señorío. La ley, por lo demás escrita y fijada para siempre, queda substraída a los cambios del tiempo; inmutable y eterna (de la que, además, los dirigentes se sienten administradores), acota el derecho divino para el que las circunstancias concretas del hombre acaban no siendo relevantes. De hecho, la situación del paralítico y del ciego no son circunstancias que hayan de ser tenidas en cuenta en la aplicación de la misma. En correspondencia, el hombre ha de definir su relación con Dios en términos de fidelidad a la ley.

De los distintos principios de los que parten Jesús y los dirigentes judíos se derivan dos actitudes éticas profundamente diversas. Mientras que para los judíos el ideal de fidelidad es la acomodación exacta de la voluntad del hombre a lo expresado, de una vez para siempre, en la ley, y entienden como pretensión blasfema cualquier intento de subordinarla a cualquier otro principio $(5,18)$, Jesús, por contra, tiene como prioridad absoluta acomodarse al modo de actuar del Padre, realizar su "designio"(8), secundando su voluntad creadora y rehabilitadora, cuyo objeto es que el hombre tenga vida $(6,40 ; c f r .5,26)$. Según él, la ley se subordina a esta prioridad y es interpretada desde ella.

Las dos actitudes se muestran irreductibles entre sí. Lo que para Jesús es la expresión de la actividad vivificadora del Padre, que liene por destinatario al hombre en cuanto necesitado, para los judíos, por el contrario, es una actuación que quebranta el mandato divino y, por lo tanto, pecado. Para Jesús, la ley está subordinada a la voluntad primera y fundante de dar vida $y$, por consiguiente, está hecha para el hombre. Para los judíos, la ley, la escrita, constituye la instancia última, como expresión de la voluntad irreformable de Dios. Para Jesús, por consiguiente, no se pueden oponer bien del hombre y voluntad de Dios, tiempo consagrado a Dios y tiempo consagrado a trabajar por la integridad del hombre. Para los judíos, sin embargo, como lo demuestran los episodios del paralítico y del ciego, esta oposición será un hecho irremediable.

Con estas premisas se entiende que Jesús apele a sus obras como el mejor testimonio de su autenticidad: "Pero el testimonio en que yo me apoyo vale más que el de Juan, pues la obras que el Padre me ha encargado llevar a término,

8. El logos, proyecto creador de Dios, dio origen a todo lo que existe $(1,3)$ y se realiza plenamente en Jesús (1, 14); el designio creador (thelêma) se concreta en la donación de la vida definitiva $(6,40)$; cfr. "Creación" en Vocabulario Teologico del Evangelio de Juan. pp. 46-53. 
esas obras que estoy haciendo, me acreditan como enviado del Padre; y así el Padre que me envió va dejando él mismo un testimonio a mi favor" (5, 36s). Pero seguidamente da un paso más en su razonamiento: en realidad, lo que lo separa de sus interlocutores es la distinta idea de Dios; de ella depende, a su vez, la interpretación que hacen de sus obras y de las Escrituras. Denuncia: "Ustedes nunca han escuchado su voz (la del Padre, cfr. 5, 37) ni visto su figura y tampoco conservan su mensaje entre ustedes; la prueba es que no dan fe a su enviado" ( $5,37 b .38$; cfr. 8, 54b.55). Por la misma razón, no entienden las Escrituras: "Ustedes estudian las Escrituras pensando encontrar en ellas vida definitiva; son ellas las que dan testimonio en mi favor $y$, sin embargo, ustedes no quieren acercarse a mí para tener vida" $(5,40)$.

La razón de la incapacidad de los dirigentes para entender las obras de Jesús y el sentido de las Escrituras es, pues, la falta de conocimiento de Dios. El texto establece un paralelismo que es revelador para comprender el razonamiento de Juan: "no conservan su mensaje entre ustedes" $(5,38)$; "no tienen el amor de Dios en ustedes" $(5,42)(9)$. Parece claro que los dos miembros del paralelismo se corresponden como causa y efecto: no conservan su mensaje (no lo conocen) porque no tienen el amor de Dios. El amor de Dios (el amor con que Dios ama y que, recibido de él, capacita para amar) abre al hombre a su conocimiento. Su ausencia incapacita para conocerlo.

El texto antepone otra observación: "Gloria humana no la acepto pero sé muy bien que ustedes no tienen el amor de Dios" $(5,41 \mathrm{~s})$. La ausencia del amor se pone de manifiesto en el afán por buscar la propia gloria. El amor es para Juan la voluntad de dar vida, dando la propia vida $(10,11.17-18)$, buscar la propia gloria es negarse a dar la propia vida $(12,23-26)$.

En resumen, las obras que Jesús presenta como el mejor testimonio del Padre sobre su autenticidad tienen un sentido: expresan el amor del Padre. Pero sólo pueden entenderse si se ama al hombre con el amor con que Dios lo ama. Es decir, si realizar la actividad (el designio) del Padre es hacerlo en el sentido y con el espíritu del Padre, estando la acción del Padre orientada al hombre y moviéndose por la misericordia y la compasión hacia él, el que no tiene el amor y compasión del Padre no puede generar una actividad como la suya. Esto es lo que reprocha Jesús a los judios: jamás entenderán su actividad, porque no tienen ese amor.

La respuesta de Jesús a la multitud desconcertada es coherente con estos principios. El episodio en el templo que registra 7, 10-24 constituye el colofón

9. Vease la correspondencia rigida de los elementos en el texto:

kai son logon / autou / ouk echese / en hymin menonta $(5,38)$

tên agapen / tou theou / ouk echete / en heausois $(5,42)$. 
de esta discusión. La multitud, atemorizada por los dirigentes que la desprecian $(7,49)$, se debate en un dilema: "La gente hablaba mucho de él cuchicheando. Unos decían: Es una persona buena. Otros en cambio: No, que extravía a la gente" $(7,12)$. Oponen dos magnitudes que no saben cómo reconciliar. Unos apelan a la bondad (cualidad relacional por definición, la cual se expresa en actitudes y obras que el destinatario experimenta como portadoras de bien); apelan, pues, a la actitud que se trasluce en su actuación: es una persona buena(10). Otros ponen en duda su doctrina y su buena fe; según ellos, Jesús aparta al hombre de la verdad (que se supone conocida); ponen en duda su ortodoxia (extravía a la gente).

Jesús aftonta con claridad la cuestión de su ortodoxia. La objeción de los dirigentes judlos: "¿Cómo sabe éste Escritura si no la ha aprendido?" $(7,15)$, manifiesta los principios en los que se fundan. Suponen que nadie que no haya aprendido, es decir, que no haya asimilado la doctrina avalada por la labor académica interpretativa de una muy larga tradición, puede saber en absoluto. La pregunta es, pues, retórica, y la respuesta, negativa: por muy brillante que parezca, ese hombre no puede saber.

La respuesta de Jesús establece el criterio de discernimiento de su doctrina según otro principio: "Mi doctrina no es mía sino del que me ha enviado. El que quiera realizar el designio de Dios apreciará si esta doctrina es de Dios o si yo hablo por mi cuenta. Quien habla por su cuenta busca su propia gloria; en cambio, quien busca la gloria del que lo ha enviado, ese es de fiar y en él no hay injusticia" (7, 16-18). Para conocer si su doctrina viene de Dios, según Juan, hay que tener una disposición previa a realizar el designio de Dios. Sorprende este razonamiento, que invierte el orden habitual de la aplicación de estos principios: la ortodoxia no se establece sólo en el interior de la doxa, sino que se convalida por la disposición a la ortopraxis. Ahora bien, la disposición a la recta actuación (que está condicionada por el grado de sensibilidad para percibir el bien del hombre o su necesidad), es la condición indispensable para la comprensión también de la doctrina(11).

10. La bondad no es fácilmente conceptualizable, se la experimenta como acto de comunicación o efusividad de la persona, la capacidad de Irasponerse al otro para com-padecer (sufrir o gozar), no sólo en compafifa del otro, sino por lo mismo que el otro, y en cuanto el motivo del dolor o del gozo es del otro.

11. Jon Sobrino, a propósito del quehacer teológico y más concretamente del "principio liberación", habla del pathos necesario que principia y orienta la reflexión teologica; más adelante postula el intellectus amoris como definición de la teologla ("La teologfa y el 'principio liberacion'", Revista Latinoamericana de Teologia, 35 (1995), pp. 116118 y $127-133$. Junto a la ortodoxia y a la ortopraxis habria que hablar de la ortopata como principio de inteligencia y no solo como consecuencia de la misma, que, siendo necesariamente relacional, para ser recta, se expresará inevitablemente como simpatfa. 
El reproche final de Jesús a los judíos cierra la discusión a modo de síntesis: "Si se circuncida un hombre el día de precepto para no quebrantar la ley de Moisés, ¿se indignan ustedes conmigo porque en día de precepto le di la salud a un hombre entero (al paralítico)? No juzguen superficialmente, den la sentencia justa" (7, 23-24). Lo que desvela la actitud de los dirigentes es que no "valoran" la salud del hombre en su integridad. Carecen del organo para ello. No sienten, por consiguiente, necesidad alguna de "encargarse de esa realidad"; por ello, acaban no interpretando ni aplicando correctamente la ley. El pensamiento de Juan al respecto podría resumirse así:

a) La aproximación a la comprensión de Jesús no se puede hacer sólo desde el flanco de su doctrina, sino ¡sobre todo! desde la comprensión de sus obras que son señales.

b) Para entender las obras de Jesús hay que entender al Padre.

c) Para entender al Padre hay que tener el amor de Dios.

d) La posesión del amor de Dios se revela en la disponibilidad para realizar su designio.

e) La disponibilidad para realizar su designio se expresa en el acto de entregar la propia vida, en el empeño de dar vida al hombre, y es incompatible con el afán de buscar la propia gloria.

\subsection{Juan 9-10}

EI texto constituye una unidad. La estructura, en sus grandes rasgos, se corresponde con la de Juan 5: (a) presentación de una actuación de Jesús y reacción negativa de los dirigentes $(9,1-38)$; (b) explicación del significado del hecho por parte del mismo Jesús $(9,39-10,39)$. Pero encontramos algunas diferencias significativas, que señalan la perspectiva propia de la sección.

En primer lugar, el hecho se presenta como una actuación conjunta de Jesús y sus discípulos(12): "Ni había pecado él ni tampoco sus padres, pero así se manifestarán en él las obras de Dios. Mienuras es de día nosotros tenemos que trabajar realizando las obras del que me envio" $(9,4 a)$. Responde a la cuestión de los discípulos que plantean el hecho de la ceguera en el plano de una discusión casi escolástica sobre la relación desgracia-culpa. Jesús lo sitúa, por el contrario, en el plano de la responsabilidad del grupo (nosotros) frente a las necesidades del hombre, y la necesidad de actuar. La actuación de Jesús que sigue ha de verse, por tanto, como el paradigma de la actuación de los que están con él.

12. La lectura plural, hêmas dei ergazesthai (nosotros tenemos que trabajar) es la mejor atestiguada por la calidad de los manuscritos y la variedad de tipos textuales que la sostienen. Siendo, además, la lectio dificilior, le asisten todas la razones para ser mantenida. 
En segundo lugar, se registra la reacción de los judios con respecto al hombre curado al que hacen blanco de sus ataques. No sucede lo mismo en el relato del paralítico, en que la figura de éste se difumina. Allf interesaba resaltar cuál era el principio de actuación de Jesús; aquí se focaliza, también, la experiencia del hombre objeto de su acción.

El hecho de la curación suscila una discusión que divide las opiniones: algunos de los fariseos comentaban: "Ese hombre no viene de parte de Dios, porque no guarda el precepto. Otros, en cambio, decían: ¿Cómo puede un hombre, siendo pecador, realizar semejantes señales?" $(9,16)$. La cuestión que subyace es la siguiente: ;la conformidad o no con la ley es la última instancia legitimadora de la actividad humana? ¿Puede el hombre apelar a otro principio de actuación más lundamental que la ley?

Ante el hecho de la curación, los dirigentes se ven en la necesidad, o bien de negarlo (lo que intentan, poniendo en duda que el hombre hubiera sido ciego); o bien, al admitirlo (hecho, a todas luces, bueno), de enfrentar lo moral y religiosamente bueno (entendiendo por esto lo hecho conforme a la ley escrita) a lo naturalmente bueno (lo humanamente plenificante, en el plano físico, psicológico, espiritual). Terminan oponiendo lo religiosamente bueno a lo bueno en cuanto plenitud humana y, en consecuencia, ponen al ciego en el trance de tener que condenar al que lo habla curado, lo que conllevaba la necesidad de renegar de su salud como algo no querido por Dios. Lo conminan, naluralmente en nombre de Dios: "Reconócelo tú ante Dios. A nosotros nos consta que ese hombre es un pecador" $(9,24)$.

El ciego, que habra dejado de serlo en todos los sentidos, apela a un principio elemental(13): lo que hace bien no puede ser malo $y$, en consecuencia, el que hace el bien no puede ser, en cuanto tal, pecador: "Si es pecador o no, no lo sé; una cosa sé, que yo era ciego y ahora veo" $(9,25)$. Se aferra al clavo ardiente del hecho mismo de la experiencia del cambio producido en él, y no se deja desalojar de esa evidencia. Con ello afima un principio: lo bueno, en el sentido de que aporta integridad al hombre, procede de Dios; Dios jamás puede ser enemigo de la plenitud humana, consecuencia ésta que, desde la óptica farisea, se hace inevitable y constituye el trasfondo más trágico del episodio. En efecto, al Dios de los fariseos le importa sobre todo la salvaguarda de su derecho y a él sacrifica al hombre. Argüir que la sumisión en esos términos es condición para la salvación es, cuanto menos, incoherente.

El ciego, guiado por la propia luz de su experiencia de curación, se toma de acusado en acusador: "Pues eso es lo raro, que ustedes no sepan de dónde

13. En el sentido de básico, fundante de toda ética. 
procede cuando me ha abierto los ojos. Sabernos que Dios no escucha a los pecadores, sino al que lo respeta y realiza su designio, a ése lo escucha... si éste no viniera de parte de Dios no podría hacer nada" $(9,30$ s.33). Juan hace gala de su reconocida ironfa: los que pretenden ver, están ciegos; el ciego ha recobrado la vista en su sentido pleno.

La solemne proclama de Jesús eleva lo sucedido a principio permanente para el devenir de la historia humana: "He venido a abrir un proceso contra el orden éste; así, los que no ven, verán, y los que ven, quedarán ciegos" $(9,39)$. Esta es la señal ante la que se bifurcan los caminos y se dividen las opciones: un hombre, el hombre Jesús, hacedor de bien, curador de paralíticos y ciegos; remediador de necesidades bien humanas como expresión del modo de presencia y relación de Dios con los hombres, quien, actuando en él, se revela como Padre. De este hombre, señal alzada en alto, expresión del amor sin límites del Padre (3, 14-17) (un amor históricamente ubicado e históricamente condicionado, tanto como concreción histórica tiene el asesinato de Jesús) se difunde una nueva luz. La suerte del hombre se decide en relación con él $(3,19-21)$. No es la ley escrita, sino un Hombre asesinado la revelación más diáfana de Dios en la historia $(1,17)$.

La advertencia de Jesús a aquellos fariseos que eran seguidores suyos ( 9 , 40), pone en guardia a todo el que dice o cree seguirlo: "Si fueran ciegos, no tendrían pecado; pero como dicen que ven, su pecado persiste" $(9,41)$. El hecho inquietante es que se puede perder el sentido de la luz y la tiniebla hasta llegar a intercambiarlos. Se puede llamar luz a la tiniebla y tiniebla a la luz (el episodio del ciego deja ejemplificada esta realidad). Es la total perturbación del órgano mismo de la visión.

La reacción de los fariseos ante la curación del ciego ha dejado al descubierto cuál es su principio de actuación. Ante la necesidad humana es donde, en última instancia, se revela el hombre que se es y el Dios en quien se cree. Los fariseos terminan expulsando de su comunidad de culto al ciego curado. No es el perfil jurídico de la medida, sino su dimensión teológica, lo que calibra Juan. Expulsando al ciego, revelan cuál es su Dios. Dios no está con ellos y el ciego lo reencuentra fuera, ien el Hombre!(14): "Se enteró Jesús de que lo habían echado fuera, fue a buscarlo y le dijo: $i$ Das tu adhesión al Hombre?...Te doy mi adhesión, Señor. Y se postró ante él" $(9,38)$.

En lo que sigue (10, 1-17), Juan traza, por contraste con los dirigentes judíos, los rasgos de Jesús. La primera parte la constituye la exposición en forma de

14. Para el significado de la expresión "el Hijo del hombre" en el Nuevo Testamento como "el hombre en su plenitud" que incluye su condición divina. cfr. J. MaleosFernando Camacho, El Hijo del hombre, Córdoba 1995; para el mismo significado en Juan $9.35 \mathrm{cfr}$. J. Mateos-J. Barreto, El evangelio de Juan. Análisis lingülstico y comentario exegético, pp. 456-458. 
parábola (10, 1-6); la segunda, la explicación de la misma $(10,7-18)$. Al expulsar al ciego, los fariseos habían acotado el espacio de Dios del que se sentran garantes: deniro o fuera, estar con Dios y sus fieles, o estar sin Dios y apartado de sus fieles, significaba estar o no con ellos. La oposición dentro-fuera constituye la isotopla que enlaza la narración precedente con la exposición que sigue.

La parábola desarrolla dos imágenes: la de la puerta del redil $(10,1 s)$ y la del auténtico pastor (10,2-5). La puerta está vista como el único lugar legítimo de acceso al redil, y a ella se contrapone cualquier otro lugar de acceso. En relación con la puerta (legitimidad) se oponen dos categorías: el que no entra por la puerta, el ladrón y bandido del cual huyen las ovejas porque no reconocen su voz $(10,1.5)$; el que entra por la puerta, el pastor, quien conoce a las ovejas y a quien las ovejas reconocen por su voz $(10,2-4)$.

Los dirigentes judfos acaban de expulsar al ciego. Literalmente: lo echaron fuera $(9,34 \mathrm{~b})$. Es un ejercicio de autoridad de los dirigentes que, dentro, se sienten responsables del espacio del que excluyen al hombre curado. Jesús denuncia la ilegitimidad de su posición: ellos están dentro ilegútimamente (no han entrado por la puerta), no pertenecen a ese sitio, están allí para robar, sacrificar y destruir $(10,10)(15)$. El significado de todo ello ha quedado patente en la conducta con el ciego curado, a ellos denuncia, pues, la aplicación de la parábola $(10,7-10)$.

La legitimidad la confiere el entrar por la puerta que es Jesús, o, lo que es lo mismo, el asumir su forma de ser, o mejor, su forma de estar entre los hombres. Esa forma de ser viene descrita con la imagen de buen pastor, como opuesto al asalariado. El buen pastor se caracteriza por el interés por las ovejas, el asalariado se preocupa sólo de sus intereses. El uno arriesga la vida por ellas, el otro, ante el peligro piensa sólo en salvar su vida $(10,11-13)$. La línea divisoria entre una categoría y la otra pasa por la disposición a entregar la vida y la negativa a hacerlo(16), no en la defensa de unos principios, sin más, sino en servicio del hombre concreto a quien se conoce y se ama: "Por eso el Padre me demuestra su amor, porque yo entrego mi vida y así la recobro. Nadie me la quita, yo la entrego por decisión propia... Este es el mandamiento que recibl del Padre" (10, 17s).

Así, pues, al buen pastor se oponen dos categorias: el ladrón que roba, sacrifica y mata; el asalariado, que huye. El uno quita la vida a las ovejas, el otro no

15. En realidad, estas acciones (robar, sacrificar y destruir) delatan que no tienen legitimidad, que no han entrado por la puerta.

16. La expresión utilizada en el original, tithèmi tên psychen $(10,15.17 .18 \mathrm{bis})$ se refiere literalmente a entregar la propia vida, esto es, a afrontar voluntariamente la muerte. En Juan se distingue de dar vida, en el sentido de comunicarla (zôên didonai, 6, 33; 10,$28 ; 17,2$ ) o vivificar (zôopoiein, 5,$21 ; 6,63$ ) cuyo efecto es que el destinalario tenga vida (zôên echein, 3, 15; 14 veces). Entregar la propia vida (tên psychên tithenai) es en Juan la condición para dar vida (zôên didonai). 
arriesga por ellas la suya propia. La propuesta de Jesús no es simplemente: frente a matar, no matar; sino, Irente a matar, dar la propia vida. Esta es la ley fundamental que, en otra parte, se la llamará nueva $(13,34)$. No consistirá en la adecuación a una mera normativa jurídica, sino en una conformación al espíritu de Jesús, clave interpretativa de toda ley.

En correspondencia con el episodio del paralítico la discusión se cierra con una consideración sobre el significado de las obras de Jesús, situada en la fiesta de la Dedicación (10, 22-39). Pero también aquí se observa una progresión significativa. La secuencia tiene dos partes. La primera $(10,22-31)$, después de señalar las circunstancias de lugar y tiempo $(10,22 s)$, comienza con un interrogatorio por parte de los dirigentes judíos, que recuerda al que fue sometido Juan Baustista $(10,24 ; c f r .1,18-18)$, sigue la respuesta de Jesús, que concluye con la afirmación de su identificación con el Padre $(10,25-30)$ y termina con la descripción de la reacción hostil de los judios $(10,30)$. La segunda parte $(10$, $32-39$ ) comienza, por el contrario, con una pregunta de Jesús $(10,32)$, a la respuesta de los judíos Jesús contesta con una argumentación que concluye, en paralelo con la primera parte, con la afirmación de la mutua "compenetración" entre él y el Padre $(10,38)$ para terminar, también como la primera parte, registrando la reacción airada de los dirigentes judíos $(10,39)$.

La pregunta que proponen a Jesús se refiere a su identidad: "Si eres tú el Ungido dínoslo abiertamente" $(10,24)$. Y, de nuevo, Jesús se remite a sus obras: "Las obras que yo realizo en nombre de mi Padre, ésas son las que me acreditan" $(10,25 \mathrm{~b} ;$ cfr. 5,36$)$, pero añade una observación desconcertante: "pero ustedes no creen porque no son ovejas mías" $(10,26)$. Se requiere, pues, una condición previa para creer: ser de sus ovejas (cfr. 10,3s). Entre sus ovejas y él se da una afinidad por la que se reconocen mutuamente $(10,27)$. Sin esta condición previa, nadie puede creer en él ni interpretar sus obras. Por ahora baste notar, con el texto, que la pertenencia a Jesús está en relación con la pertenencia al Padre, que es el que se las entrega $(10,29)$. Más abajo volveremos sobre el tema.

La respuesta termina con una afirmación rotunda: "Yo y el Padre somos uno" $(10,30)$, que provoca la misma reacción escandalizada que la explicación dada en su momento a la curación del paralítico: "Los dirigentes cogieron de nuevo piedras para apedrearlo" $(10,31)(17)$.

17. En efecto, después de la curación del paralítico habf́a dicho: "Mi Padre sigue trabajando y yo lambien Irabajo" $(5,17)$; la reacción de los dirigentes se expresa en estos términos: "En vista de esto los dirigentes judíos trataban de matarlo, ya que no sólo suprimfa el descanso de precepto, sino también llamaba a Dios su propio Padre, haciéndose él mismo igual a Dios" $(5,18)$. En aquella ocasión se escandalizan porque creen que, por su modo de hablar y actuar, Jesús se hace igual (ison) a Dios; aquí Jesús se identifica (hen) con el Padre. 
Ante la reacción escandalizada de los judíos Jesús comienza en la segunda parte llamando de nuevo la atención sobre sus obras. La unidad entre él y el Padre se percibe en la comunidad de acción. La actividad a la que Jesús apela no es simplemente una actividad como la del Padre, sino que es la del Padre. Y ante el escándalo de los judíos, Jesús insiste: la condición de Hijo se manifiesta en las obras $(10,34 s ; c f r .5,19-23)$ y añade: "Si yo no realizo las obras de mi Padre, no me crean; pero si las realizo, aunque no me crean a mi, crean a las obras" (10, 37-38a). En consecuencia, Jesús no sólo es el portador de un mensaje del Padre, sino que es expresión del Padre mismo, en cuanto éste está presente y actúa en él. Por ello, son las obras las que revelan la íntima "compenetración" entre él y el Padre: "Crean a las obras; así sabrán de una vez que el Padre está identificado conmigo y yo con el Padre" $(10,38)$, concluye.

Convendría notar que en Juan la "compenetración" entre Jesús y el Padre se hace extensiva, de forma análoga, a sus discípulos: "que sean todos uno como tú, Padre, estás identificado conmigo y yo contigo, para que támbién ellos lo estén con nosolros" $(17,21-23)(18)$.

En lo que concierne al tema del discernimiento de las señales se pueden resumir los principales puntos contenidos en la enseñanza de Juan en los siguientes:

a) Que se puede perder el órgano de la visión hasta el punto de llegar a confundir la luz con la tiniebla y la tiniebla con la luz. Es decir, se puede perder el sentido de lo bueno y lo malo hasta el punto de intercambiarlos.

b) Que no se puede enfrentar lo bueno en cuanto definido por la ley (tampoco por la divina) a lo bueno en cuanto integridad humana.

c) Que, en consecuencia, todo el ordenamiento moral tiene como punto de autentificación la respuesta a la necesidad humana.

d) Que la reacción ante la necesidad humana, tal cual viene ejemplificada, por una parte, en la clase dirigente judía y, por otra, en Jesús, deslegitima o legitima ante Dios a las personas o instituciones que representan.

e) Que la medida de la autenticidad de la preocupación por el hombre la da la disposición a entregar por él la propia vida.

f) Que ese principio tenido como absoluto y actuado en la práctica, no sólo no lesiona el derecho divino, sino que revela el modo de presencia y actuación de Dios como Padre y, paralelamente, manifiesta la condición de hijo de Dios del que tal hace.

18. A la afirmación de Jesús sobre sí mismo: "Yo y el Padre somos uno" (hen esmen; 10 , 30) responde la petición por sus discípulos: "Que sean todos uno (hen ôsin) como tú, Padre, estás identificado conmigo y yo contigo" $(17,21)$. Es evidente que, en uno y otro caso, la común identificación se expresa necesariamente en la actividad común. 


\section{Una cuestión de fondo: la experiencia de Dios}

Tanto en una como en otra sección de las analizadas se advierte que la condición previa para entender el significado de la enseñanza y proceder de Jesús es, en un caso, la disposición a realizar el designio del Padre $(7,17)$ y, en el otro, la condición de ser ovejas de su rebaño $(10,26)$, hecho éste que compete al Padre, puesto que él es el que entrega las ovejas a Jesús $(10,29)$. Se ha notado, además, que en 5, 38-42 se reprocha a los que no entendieron la curación del paralítico no conocer a Dios. La falta de conocimiento de Dios se relaciona con la carencia del amor que se recibe de él, y ésta, a su vez, con la búsqueda de la propia gloria.

En la discusión que se entabla en torno a Jesús después de la multiplicación de los panes y su afirmación de ser el pan de vida, él establece los principios siguientes: "Todo el que el Padre me entrega llega hasta mí" $(6,37)$, "Nadie puede llegar hasta mí si el Padre que me ha enviado no tira de él" $(6,44)$, "Todo el que escucha al Padre y aprende se acerca a mí $(6,45)$, "Nadie puede llegar hasta mí si el Padre no se lo concede" $(6,65)$.

La actividad del Padre con respecto al hombre mira a Jesús y viene descrita de múltiples formas: enseñar al hombre de modo que éste se acerque a Jesús (6, $45)$; llevarlo a Jesús $(6,37)$, manifestándose incluso como fuerza de atracción $(6,44)$; en lodo caso, acercarse a Jesús es un don del Padre $(6,65)$. Para Juan, por tanto, hay una relación previa con el Padre, sin la cual no se puede acceder al conocimiento de Jesús. Esa relación previa se la describe en términos de aprendizaje del Padre y es correlativa a la actividad didáctica universal de éste: "serán todos discípulos de Dios" $(6,45 ;$ cfr. Is 54, 13)(19).

La enseñanza universal de Dios está inserta en el corazón del hombre desde su creación, puesto que la Palabra-Sabiduría de Dios, por la cual todo fue hecho $(1,3)$, contenfa vida y la vida era la luz de los hombres $(1,4 s)$. En todo caso, una vez restablecida la afinidad con la vida que la Palabra creadora infunde en el hombre, éste entiende (ve) con claridad a Jesús y lo percibe como la Palabra hecha realidad humana, cuyo contenido es la gloria del Padre, plenitud de amor y lealtad $(1,14)$; es más, se siente impelido hacia él como por una fuerza irresistible (tira de él, 6, 44)(20).

Puesto que la Palabra es creadora $(1,3)$, el hombre aprende del Padre, ante todo, su modo de actuar (cfr. 5, 17-21). En consecuencia, es ante la vida 0 ante

19. En Isafas, la expresión describe el ideal utópico de la restauración, no porque la enseñanza de Dios se reserve a esos tiempos, sino porque en ellos, al fin, el hombre será capaz de aprender.

20. La expresión del texto helkyse ("tirar", "arrastrar") se encuentra de nuevo para describir la fuerza que ejerce Jesús como señal alzada: "pues yo cuando sea levantado de la tierra tirart (helkysó) de todos hacia mf" $(12,32)$. 
su ausencia la muerte, la enfermedad, la degradación del hombre, donde se pone de relieve si el hombre ha aprendido del Padre o no. La sensibilidad ante la vida (o la muerte) está en proporción directa con el amor y la misericordia, que definen a Dios como Padre y que de él se reciben.

Pero la denuncia dramálica que recorre el evangelio es que se puede pervertir el concepto de Dios hasta el punto de intercambiarlo por un principio de muerte y de mentira (ien este orden: muerte y mentira!)(21): "Si Dios fuera Padre de ustedes, ustedes me querrfan a mí... ¿Por qué razón no entienden mi lenguaje?... Ustedes proceden de ese padre que es el Enemigo, y quieren realizar los deseos de su padre. El ha sido homicida desde el principio y nunca ha estado en la verdad... El que procede de Dios escucha las exigencias de Dios; por eso ustedes no escuchan, porque no proceden de Dios" $(8,42-47)$.

Continúan en pie las instituciones, pero el sistema religioso es como una partitura a la que se ha transportado de clave: se sigue invocando la alianza, pero falta el vino del amor (2,1-12); en el templo el culto conserva su aparente esplendor, pero el templo mismo es una casa de negocios, no del Padre $(2,16)$, recinto de las fiestas de un dios desentendido de las miserias de los hombres (5, $1-5)$, cuya conservación sirve como pretexto para el asesinato de Jesús $(11,48)$; se sigue invocando la ley, pero en manos de los dirigentes se ha convertido en "su" ley $(8,17 ; 10,35 ; 15,25)$, esto es, de una minoría que la interpreta desde la situación de poder en la cual están instalados y desprecian a la gente común (7, 48-49), expresión de la voluntad de un dios inmisericorde que, por lo mismo, no es el Padre de Jesús $(5,1-18 ; 9,13-34)$, una ley, en fin, instrumento de asesinato $(19,7 ; c f r .16,2)$.

Una de las advertencias más graves del evangelio de Juan se refiere al solaparse del enemigo en las instituciones religiosas judías: alianza, templo, ley, de modo que quedan al servicio y como expresión de un sistema de muerte. De hecho, la muerte de Jesús es para Juan no sólo la manifestación del Padre, sino la prueba de la verdadera naturaleza del sistema al que desenmascara, desvelando que el principio que lo anima es un principio de muerte. Frente al veredicto de ese sistema(22), en el que Jesús resulta convicto de pecado contra la ley y

21. Este orden está en consonancia con la afirmación del prólogo: "Y la vida era la luz de los hombres" $(1,4)$, donde la vida es el concepto sustantivo y la luz (la verdad) el adjetivo; esto es, la verdad no es otra cosa que la evidencia de la vida; $c f r$. J. MateosJ. Barreto, El evangelio de Juan Análisis lingǘistico y comentario eregético, pp. 58-60.

22. El lexema griego kosmos tiene un sema de organización. Se usa de hecho para referirse a la organización polftica y social, cfr. Platón, Leg. 8, 846d; Prot. 322c; también Tuc. 3, 77; 8, 48.67.72; Aristót., Pol. 5, 7p, 1307b. En Juan es característico y muy frecuente el sentido de humanidad en cuanto estructurada en un orden socioreligioso enemigo de Dios, es decir, contrario al designio creacional de Dios. Ese mundo tiene su expresión emblemática, de hecho, en el sistema político-religioso 
rechazado por Dios, "el valedor" asegura que el asesinato de Jesús representa la misma condena del mundo, que sigue asesinando en nombre de Dios (16, 1-11).

Todo el evangelio de Juan se puede considerar como una reivindicación del verdadero Dios. En un doble sentido: afirmando la superioridad de la nueva economía con respecto a la antigua (verdadero como opuesio a imperfectamente conocido)(23) y denunciando, como se ha dicho, la perversión de las instituciones que implica la introducción subrepticia en ellas de un dios principio de asesinato y de mentira (verdadero como opuesto a falso) y que convierte en instrumento de muerte lo que debió ser instrumento de vida.

Ya desde el prólogo se hace una afirmación de principio que enlaza el antiguo credo con el relato evangélico: "A la divinidad nadie la ha visto nunca; un Hijo único, Dios, el que está de cara al Padre, él ha sido la explicación $(1,18)$ ". La estructura de esta frase, construida en paralelo con la afirmación anterior, subraya la intención de Juan:

a) porque la ley se dió por medio de moisés

b) el amor y la lealtad han existido a) Nunca a la divinidad nadie la ha visto

b) un Hijo único, Dios, el que está de cara al Padre, él ha sido la explicación $(1,18)$.

Moisés había sido el mediador de la antigua alianza, transmitió la Ley pero le estuvo vedado contemplar el rostro de Dios; cuando a petición suya pasó la gloria de Dios, sólo pudo contemplar su espalda, pero el rostro no lo pudo ver (Ex 33, 22s; 34, 6.8). Jesús es la misma Palabra mediante la que se hizo el

judío. En ningún caso hay que entender este juicio negativo como el rechazo del pasado de fe del pueblo -Juan afirma que el templo es la casa del Padre $(2,16)$, que la salvación viene de los judíos $(4,22)$, que las Escrituras hablan de Jesús $(5,39)$-. sino que se refiere a la perversión de las instituciones, que en manos de sus dirigentes no sólo han sido desnaturalizadas, sino cambiadas de signo. La traducción en estos contextos de kosmos por "mundo" serfa menos adecuada para expresar la idea de Juan; cfr. "Mundo", J. Mateos-J. Barreto, Vocabulario Teológico del Evangelio de Juan, pp. 211-215.

23. Juan toma distancia de las instituciones judfas que considera sobrepasadas por la revelación de Dios-Padre tal cual se manifiesta en Jesús. En este sentido, han de entenderse expresiones tales como era la luz, la verdadera $(1,9)$; él les da el pan del cielo, el verdadero $(6,32)$; Yo soy la vid, la verdadera $(15,1)$; que te conozcan a $t_{\text {, }}$ el solo verdadero Dios (17, 3). En todos los casos (efr. también 1Jn 2, 8), el artículo que acompaña al adjetivo tiene valor diacrítico (entre las/los tenidos como tales, la/el verdadero), en un contexto polémico que manifiesta uno de los principios que va articulando el pensar teológico de la primera comunidad: el principio de la excelencia de las realidades nuevas (verdaderas, perfectas, definitivas) con respecto a las antiguas (imperfectas, provisionales) a las que sustituyen (cfr. Heb 8, 2). 
mundo. En cuanlo hecha (expresada en la) realidad humana, él hace presente la gloria del Padre (amor y lealtad, 1,14)(24), que llega a existir en medio de los hombres por medio de él. A la oposición Moisés-Jesús Mesías, corresponde la de Ley-amor y lealtad. La revelación plena de Dios es la del amor y la lealtad tal cual se expresan en un hombre: Jesús Mesías. La nueva economía supera a la antigua precisamente en ese punto: lo que Dios es, se hace visible(25) en un hombre. Ahora bien, según Juan, lo que Dios es se manifiesta en lo que Dios hace en y por medio de un hombre. El lenguaje sobre Dios no lo articula Jesús sólo por medio de discursos sino, sobre todo, por su obras. Y no cualesquiera, el signo por excelencia es la entrega de su vida como expresión de su amor (13, 1; $15,13)$. Por eso proclama en el umbral de su muerte, advirtiendo del valor teofánico del hecho: "Padre, ha llegado la hora: manifiesta la gloria de tu Hijo, para que el Hijo manifieste la tuya... y ésta es la vida definitiva: que te conozcan a ti, el único Dios verdadero, conociendo a tu enviado, Jesús Mesías" (17, lb.3)(26). Juan identifica el conocimiento de Dios con el de su enviado en el aclo de entregar la vida. El paradigma se reduce a la vida o a la muerte, esto es, a matar o hacer vivir, entregar la vida o arrebatarla.

Al Padre se lo "ve" en Jesús y todo discurso sobre Dios ha de remitirse a dar explicación de ese Hombre. Así se lo muestra a Felipe cuando le pide lo que ha

24. Ese es el contenido del articulo de fe que constituye el clímax del credo del llamado prólogo de Juan. En efecto, Jn 1, 1-18 responde más bien al género literario de credo: Carece de los elementos doxológicos propios del himno y, por el contrario, son característicos los elementos testimoniales que proclaman la propia experiencia $(1,14.16)$, en lo que constituye una síntesis de la historia de la salvación. El momento privilegiado de la contemplación de la gloria es la muerte de Jesús en la cruz. A ese momento se refiere, sin duda, el testimonio recogido en la profesión de fe: "Hemos contemplado su gloria" $(1,14)$. Por lo mismo, habría que contemplar el valor complexivo y no incoalivo de los aorislos (sarx egeneto kai eskênôsen): a ambas realidades se las contempla, desde el recuerdo de la comunidad, como hechos consumados en su muerte. El griego sarx no tiene aquf un sentido metaffsico, sino existencial: la condición humana en cuanto débil que se revela como tal sobre lodo en la muerte.

25. No en vano, en relación con la manifestación de Dios en Jesús Mesías, el tema de la visión liene en Juan un desarrollo muy particular. En efecto, dentro del campo semántico de la visión, se articulan algunos de los símbolos más caracteristicos de evangelio como: luz-tiniebla, dia-noche, ceguera-visión, presencia-ausencia.

26. "... conociendo a tu enviado Jesús Mesfas". La coordinación se ha de entender como modal, donde el verbo de la coordinada (el mismo de la oración anterior) se encuentra implícito; la coordinada expresa el modo con que se realiza la oración principal: Esta construcción es frecuente, tanto en el griego helenístico como en el clásico, cfr. Angel Ußbán, "La coordinada modal", FN 2 (1988), p. 78. La afirmación ha de entenderse en relación con otras del evangelio: "Cuando uno me da su adhesion, no es a mí a quien la da, sino al que me ha enviado y cuando uno me ve a mí ve al que me ha enviado" $(12,44 s)$. "El que me ve a mí está viendo al Padre" $(14,9)$. 
sido el empeño permanente del hombre, la visión de la divinidad: "Señor, haz que veamos al Padre, y nos basta. Le contestó: Tanto tiempo llevo con ustedes y ¿no has llegado a conocerme, Felipe? Quien me ve a mi eslá viendo al Padre... ¿No crees que yo estoy identificado con el Padre y el Padre conmigo? ... Es el Padre quien, viviendo en mI, realiza sus obras" $(14,8-10)$.

Conviene notar que la "gloria" de la que aquí se habla como don del Padre al Hijo $(1,14)$, es participada por la comunidad de creyentes: "Yo, por mi parte, la gloria que tú me has dado se la he dado a ellos, para que sean uno como nosotros somos uno" $(17,22 ; c f r .1,16)$; de modo que la función teofánica se transfiere también a la comunidad. La "gloria", por tanto, no designa la condición divina en abstracto, halo misterioso, transcendencia metafísica de Dios. Está identificada con el "amor fiel" y éste queda expresado en el tiempo y en medio de un conflicto hasta la muerte. Es un amor ubicado históricamente.

Por eso, a la "gloria" no se la comprende desde la oposición categorial divino versus humano. No se opone a humanidad, simplemente, sino al odio u opacidad del mundo, a la tiniebla $(1,4)$. "Gloria-amor y odio", no son estados, sino fuerzas contrapuestas: creación-vida versus destrucción-muerte; ni representan un contraste meramente ético-espiritual; tienen una dimensión social, se expresan en el plano de las estructuras socio-religiosas.

La contemplación de la gloria a la que se refiere la profesión de fe $(1,14)$ no es pura contemplación metafísica, sino la efectiva contemplación del amor de Dios en el amor humano de Jesús, sobre todo en la ultimidad de la muerte (13, 1). En esta línea se revela la coherencia de la versión que 1 Juan 4,12 hace del texto del prólogo antes citado. Véase el paralelismo entre ambos:

a) A la divinidad nadie la ha visto nunca;

b) Un Hijo único, Dios el que está de cara al Padre, él ha sido la explicación (jn 1, 18). a) A la divinidad nadie la ha contemplado nunca;

b) Si nos amamos mutuamente, Dios habita en nosotros y su amor queda realizado en nosotros ( $1 \mathrm{Jn} 4,12)$.

Al mismo principio, formulado de idéntica manera ("a la divinidad nadie la ha visto nunca"), siguen dos observaciones, en uno y en otro caso, al parecer distintas, pero más relacionadas entre sí de lo que aparentemente parecen. El lugar que ocupa en el evangelio la revelación por medio del Hijo, lo ocupa en la carta la experiencia de Dios en el ejercicio del amor fraterno. Este, tal cual lo entiende IJuan (3, 16-18; cfr. 1, 3-6), es la única forma de experiencia de Dios y el modo de hacerlo presente y manifiesto.

El amor en Juan, que se describe como sensibilidad ante la vida (o la muerte) y que se activa ante la necesidad humana, alineándose con la voluntad creadora 
y rehabilitadora de Dios, no es sólo consecuencia, sino principio de conocimiento. En un doble sentido: principio de conocimiento pasivo (aprehensión de la realidad divina) y principio de conocimiento activo (manifestación de la misma). El trayecto que lleva desde la aprehensión de la necesidad del hombre hasta la respuesta a ella, significa para el hombre la oportunidad, no sólo de conocer, sino de "compenetrarse" con el Padre y el Hijo que se dejan alcanzar en ese mismo trayecto y en esa misma dirección. 